\title{
USO DO APLICATIVO DECIBELÍMETRO SOUND METER PARA O ESTUDO DA DIRETIVIDADE DO SOM: UMA ABORDAGEM PARA O ENSINO MÉDIO
}

\author{
${\text { Lídia da Rocha Silva }{ }^{1} \text { e Bianca Martins Santos }}^{1}$ \\ ${ }^{1}$ Universidade Federal do Acre (UFAC)
}

Palavras-Chave: Ensino de física; Aplicativo Decibelímetro Sound Meter; Diretividade do som.

\section{Introdução}

$\mathrm{O}$ atual modelo de ensino tradicional vem sendo questionado em esfera geral, grande parte desses questionamentos são norteados pela inadequação do método (DARROZ; ROSA; GHIGGI, 2015), ou seja, os recursos utilizados não condizem com a realidade do perfil atual de aluno. Os alunos nas diferentes faixas etárias tem acesso direto à informação no próprio smartphone, tal liberdade de acesso à informação (SELIGMAN; CHRISTOFOLETTI, 2011) criou um tema de discussão entre o interesse do aluno e as ferramentas utilizadas pelos professores para fazer a abordagem dos conteúdos na disciplina de física.

A adequação gradativa das salas de aulas por meio da tecnologia de informação e comunicação, através de instrumentos facilitadores de acesso e difusão da informação como: computador, projetor, caixas de som, internet e celulares; têm permitido algumas possibilidades de mudança na forma de ensinar os conteúdos. Tais espaços dinâmicos de interação utilizam linguagem visual e sonora, estimulam o processamento de informações dando certa autonomia na busca de conhecimento e gerando impacto imediato sobre os discentes. Condições que podem favorecer a aprendizagem e que muitas vezes não são desenvolvidas dentro da própria sala de aula. Neste sentido,

Materiais didáticos digitais de apoio à aprendizagem vêm sendo cada vez mais produzidos e utilizados em todos os níveis de ensino. Esses materiais são chamados Objetos de Aprendizagem - OA. Repositórios de OA proliferam na Internet, colocando à disposição do usuário, recursos educacionais para facilitar a aprendizagem tanto no ensino a distância quanto no apoio ao ensino presencial. (ARANTES; MIRANDA; STUDART, 2010, p. 27).

É possível estabelecer uma relação direta entre smartphones e práticas pedagógicas que facilitem o processo de ensino e aprendizagem? Por entender as dificuldades enfrentadas no contexto escolar, especificamente na área de física, e considerando a acessibilidade dos alunos à celulares smartphones (HAWLEY; MCCLAIN, 2018), têm-se o desafio de promover com estratégia didática a inserção de aplicativos no contexto estudantil, com a finalidade de melhorar a compreensão sobre os conteúdos de física, uma vez que os alunos já estão familiarizados com este equipamento.

\section{Metodologia e Material}

O trabalho propõe a aplicação da sequência didática (Tabela 1), dividida em sete etapas desenvolvidas ao longo da aula. Tem como objetivo utilizar o aplicativo decibelímetro para esclarecer conceitos de ondas sonoras e visualizar a diretividade do som através do gráfico polar. A Figura 1 apresenta o aplicativo a ser utilizado na sequência (parte-a) e um exemplo com dados experimentais do gráfico da variação da diretividade do som (parte-b).

Tabela 1: Etapas da sequência didática

\begin{tabular}{|c|l|c|}
\hline $\begin{array}{c}\text { Etap } \\
\text { a }\end{array}$ & \multicolumn{1}{|c|}{ Descrição } & Tempo \\
\hline $1^{\circ}$ & Aplicação do questionário inicial & $15 \mathrm{~min}$ \\
\hline $2^{\circ}$ & $\begin{array}{l}\text { Apresentação do aplicativo Decibelímetro Sound Meter, finalidade e uso e } \\
\text { da escala de decibéis }\end{array}$ & $10 \mathrm{~min}$ \\
\hline $3^{\circ}$ & Abordagem do conteúdo ondas sonoras e diretividade do som & $25 \mathrm{~min}$ \\
\hline $4^{\circ}$ & $\begin{array}{l}\text { Realização do experimento com aplicativo Decibelímetro Sound Meter para } \\
\text { medir a intensidade do som, a parte de coleta de dados }\end{array}$ & $30 \mathrm{~min}$ \\
\hline $5^{\circ}$ & Análise dos dados coletados e construção do gráfico polar & $10 \mathrm{~min}$ \\
\hline
\end{tabular}




\begin{tabular}{|l|l|l|}
\hline $6^{0}$ & Discussão das fenômenos físicos através do gráfico da diretividade do som & 10 min \\
\hline $7^{0}$ & Aplicação do questionário final & $20 \mathrm{~min}$ \\
\hline
\end{tabular}

Figura 1 - Aplicativo Decibelímetro Sound Meter (parte-a). Gráfico polar da diretividade do som (parte-b)

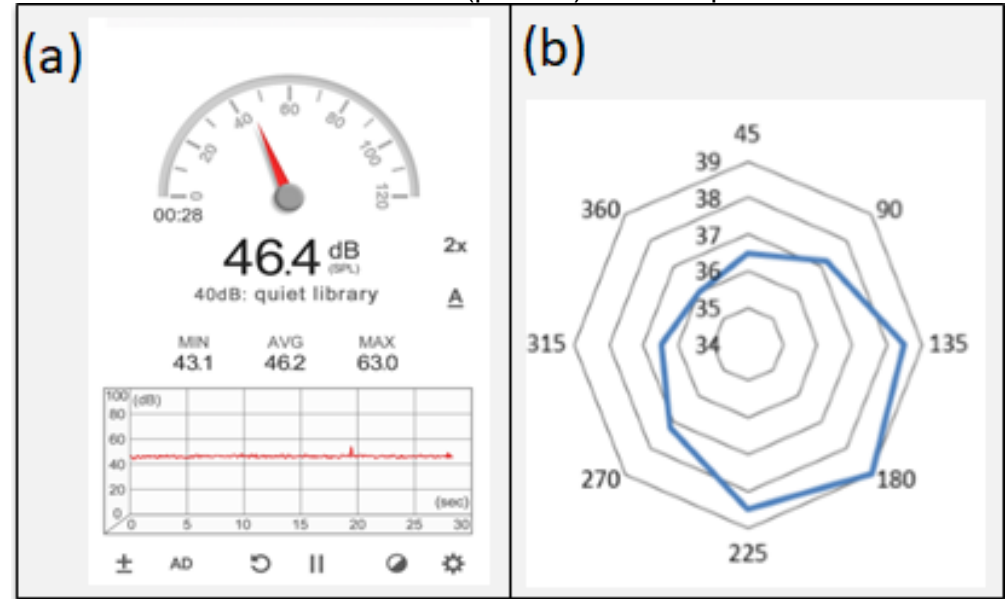

Fonte: Print da tela do aplicativo (parte-a); Próprio autor (parte-b).

As etapas iniciais seguem um modelo de aula expositiva, a novidade está apresentada na $4^{\circ}$ e $5^{\circ}$ etapa. A $4^{\circ}$ etapa consiste em medir as variações da intensidade do som através do aplicativo. As variações de intensidade ocorrem em função das variações angulares (previamente estabelecidas) da fonte sonora que emitirá frequência constante de $1 \mathrm{kHz}$. A 5o etapa será a construção do gráfico polar a partir dos dados de intensidade $(\mathrm{dB})$ e ângulo $\left(^{\circ}\right)$. O raio representado no gráfico será o nível de entrada do som em decibéis e o ângulo representará a orientação da fonte sonora em relação aos sensores do celular. Através da realização da $4^{\circ}$ e $5^{\circ}$ etapa espera-se bom desempenho dos alunos nas etapas finais.

\section{Resultados esperados}

$\mathrm{Na}$ direção de cooperar para um ensino de Física mais dinâmico durante o ensino médio, o trabalho fará uma abordagem didática quanto ao uso de smartphones utilizando o aplicativo Decibelímetro Sound Meter. Pretende ensinar a escala de decibéis, apresentar os conceitos de onda e visualizar na prática o comportamento da onda sonora via experimento proposto. Deste modo tem por finalidade, proporcionar a liberdade entre os processos de construção do conhecimento, onde se ampliará o embasamento teórico-prático na área de tecnologias de informação aplicadas ao ensino de física.

\section{Referências}

DARROZ, L. M.; ROSA, C. W.; GHIGGI, C.M. Método Tradicional x Aprendizagem Significativa: Investigação na ação dos professores de Física. Meaningful Learning Review, Passo Fundo, v. 5, n. 1, p. 70-85, 2015.

SELIGMAN, L.; CHRISTOFOLETTI, R. Tecnologias, mídia e educação: Percursos teóricos entre a sociedade da informação e a sociedade do conhecimento. Imagens da educação, Maringá, v. 1, n. 1, p. 57-64, 2011.

ARANTES, A. R.; MIRANDA, M. S.; STUDART, N. Objetos de aprendizagem no ensino de física: Usando simulações do PHET. Física Na Escola, São Paulo, v. 11, n. 1, 2010.

HAWLEY, S.H; MCCLAIN, R. E. Visualizando a diretividade do som via smartphones sensors. The Physics Teacher, v. 56, 2018. 